\title{
A Rare Cause of Liver Cirrhosis: Multiple Myeloma
}

\author{
Fatiha Bellouhou ${ }^{2 *}$, Fatima Ezzahra Haddar ${ }^{2}$, Ghita Beddou ${ }^{3}$, Chakour ${ }^{3}{ }^{3}$, Adil Ait Errami ${ }^{2}$, Sofia Oubaha ${ }^{1}$, Zouhour \\ Samlani ${ }^{2}$, Khadija Krati ${ }^{2}$
}

\footnotetext{
${ }^{1}$ Physiology Department, Faculty of Medicine and Pharmacy at Cadi Ayyad University, Marrakech

${ }^{2}$ Gastroenterology Department, Mohammed VI University Hospital, Marrakech

${ }^{3}$ Biological hematology, Military hospital Avicenne of Marrakech
}

DOI: $10.36347 /$ sjmcr.2020.v08i07.005

| Received: 06.01.2020 | Accepted: 13.01.2020 | Published: 18.07.2020

*Corresponding author: Fatiha Bellouhou

Abstract

The clinically reported case of liver involvement with multiple myeloma (MM) is rare. Relatively, most of the reported unusual manifestation of MM has been in autopsied series; since far, the data around diagnosis, clinical feature, treatment, and prognosis of patients are still unknown. We report a case of a 73-year-old patient with MM who is admitted for upper gastrointestinal haemorrhage made of hematemesis of medium abundance with anemic syndrome, hepatomegaly with ascites of average abundance .Elsewhere osteo-articular examination is without abnormality. Initial laboratories included elevated liver function tests (aspartate aminotransferase $3 * \mathrm{~N} \mathrm{U} / \mathrm{L}$ and alanine aminotransferase $2 * \mathrm{~N} \mathrm{U} / \mathrm{L}$ ) and normocytic normochromic anemia nonregenerative (HB to $09.5 \mathrm{~g} / \mathrm{dl}$, reticulocyte rate to $20000 / \mathrm{mm}^{3}$ ) with cholestasis $(\mathrm{GGT}=7 * \mathrm{~N}, \mathrm{PAL}=5 * \mathrm{~N}, \mathrm{BT}=3 * \mathrm{~N}$ predominantly direct). A myelogram with karyotype was made having concluded a plasmocyte infiltration at $20 \%$ consisting of dystrophic plasma cells.A liver biopsy revealed a diffuse portal and sinusoidal infiltration of plasma cells. In this report, we review the literature of liver involvement in multiple myeloma.

Keywords: Multiple myeloma, Hepatic involvement amyloidosis.

Copyright @ 2020: This is an open-access article distributed under the terms of the Creative Commons Attribution license which permits unrestricted use, distribution, and reproduction in any medium for non-commercial use (NonCommercial, or CC-BY-NC) provided the original author and source are credited.

\section{INTRODUCTION}

Multiple myeloma (MM) is a clonal B-cell malignancy characterized by the aberrant proliferation of plasma cells within the bone marrow (BM). However, the disease typically remains confined to the BM [1]. A small number of patients develop extramedullary disease at diagnosis, at progression, or during relapse phase.

Extra-osseous manifestations of multiple myeloma (MM) are common and polymorphic. However, liver involvement remains rare. Etiopathologically, it is often related to a deposition of amyloid substances. Hepatic myeloma is exceptional; only 4 cases have been reported in the literature.

Relatively, most of the reported unusual manifestation of MM has been in autopsied series; Since far, the data around diagnosis, clinical feature, treatment, and prognosis of patients are still unknown.[2] We report a new case of myelomatous liver cirrhosis with literature review of liver involvement in multiple myeloma.

\section{OBSERVATION}

This is a 73-year-old patient with risk factors for viral transmission, chronic smoker, cholecystectomized 2 years ago who is admitted for upper gastrointestinal haemorrhage made of hematemesis of medium abundance associated with atypical epigastralgia.

The clinical examination on admission found an anemic syndrome, hepatomegaly with ascites of great abundance. Elsewhere osteo-articular examination is without abnormality. The biology reveals a normochromic normocytic nonregenerative anemia (HB $=09.5 \mathrm{~g} / \mathrm{dl}$, reticulocyte $=20000)$. The liver test showed evidence of hepatocellular insufficiency (TP $=$ $60 \%$, Albumin $=18.4 \mathrm{~g} / \mathrm{dl}$ ) with moderate cytolysis $($ ASAT $=3 * \mathrm{~N}$, ALAT $=2 * \mathrm{~N})$ and cholestasis $(\mathrm{GGT}=$ $7 * \mathrm{~N}, \mathrm{PAL}=5 * \mathrm{~N}, \mathrm{BT}=3 * \mathrm{~N}$ predominantly direct). Renal function and phosphocalcic balance were correct. The electrophoresis of the proteins found $\gamma$ globulins at $11.5 \mathrm{~g} / 1$ and $\beta$ globulins at $10 \mathrm{~g} / 1$.

The ascitic fluid analysis showed a transudate fluid ( $2 \mathrm{~g} / \mathrm{L}$ proteases) with no increase or abnormality 
of the cellularity (30 elements / $\mathrm{mm} 3$ including $2 \%$ of neutrophils, $50 \%$ of lymphocytes and $48 \%$ of macrophage cells).

A myelogram with karyotype was made having concluded a plasmocyte infiltration at $20 \%$ consisting of dystrophic plasma cells. Faced with the negativity of the etiological assessment: the serologies of viral hepatitis $\mathrm{B}$ and $\mathrm{C}, \mathrm{CMV}, \mathrm{EBV}$, as well as the herpes and the immunological assessment were all negative, a liver biopsy-puncture was performed. She had concluded that hepatic cirrhosis was associated with plasma cell infiltration. There was no evidence for systemic amyloidosis, particularly in the liver. Therefore, this hepatic cirrhosis was directly attributed to the MM .The diagnosis of multiple myeloma was thus retained.

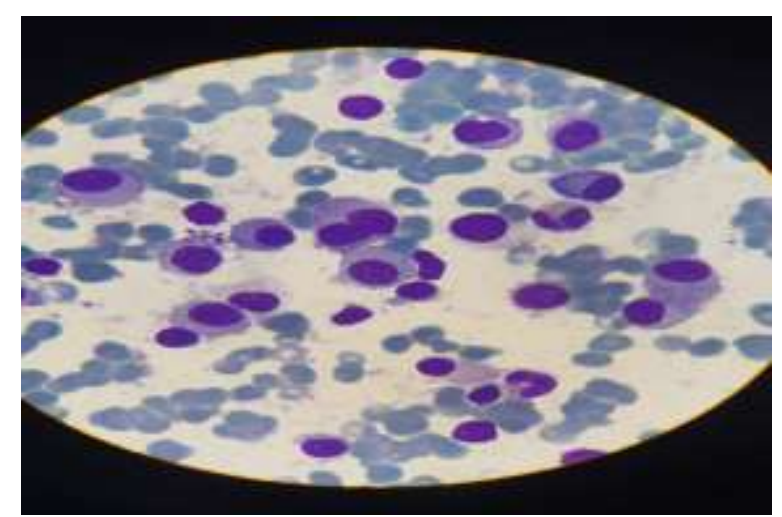

Fig-1: Myelogram test shows increased levels of dystrophic plasma cells

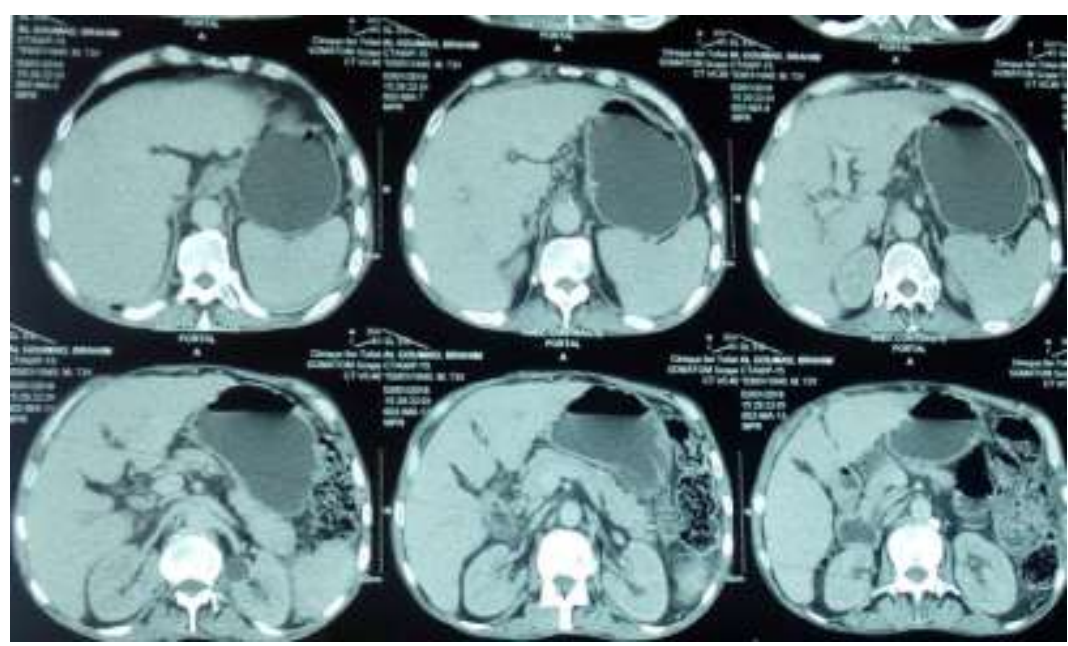

Fig-3: Abdominal CT scan showing liver cirrhosis with portal hypertension

\section{DISCUSSION}

Extra-medullary involvement in patients with multiple myeloma ranges from $6 \%$ to $17 \%$. [3.1] Skin and liver are the most frequent localization [3.4]. Liver dysfunction in multiple myeloma patients is mainly due to amyloidosis and more rarely massive plasma infiltration or light chain deposition disease $[3,1,5,6]$.

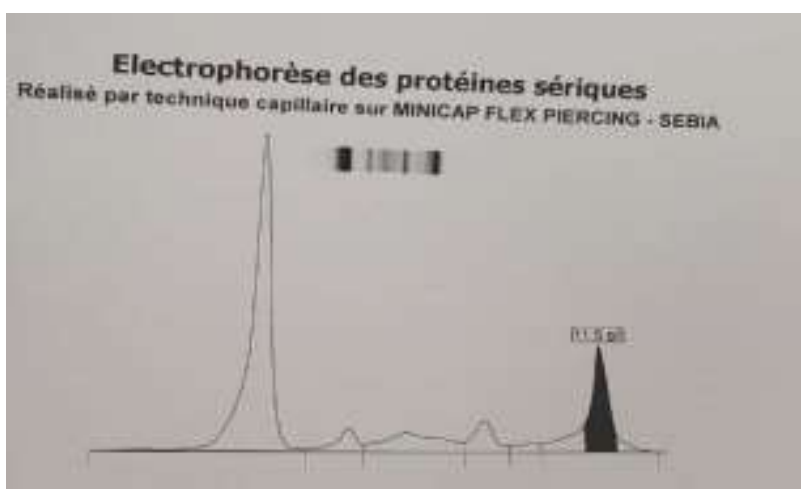

Fig-2: Serum protein electrophoresis finds a monoclonal gammopathy peak

Radiological assessment of the skeleton was performed without showing lytic lesions. Ultrasound and abdominal CT reveal a dysmorphic liver of chronic liver disease with signs of portal hypertension and ascites of average abundance without dilatation ofthebile ducts nor splenomegaly. Digestive fibroscopy had shown grade I and II oesophageal varices with red signs and hypertensive gastropathy. based on systemic chemotherapy. The current evolutionary decline was 1year and a half. Evolution was marked by stabilization of both multiple myeloma and hepatic cirrhosis. 
In a retrospective autopsy series of 128 patients with MM [9] Perez-Soler and al. Reported the clinical and pathological characteristics of Hepatic impairment. This study showed diffuse infiltration of the liver by plasma cells in 10 of 21 patients with liver tissue involvement. Thomas and al studied autopsies of 64 patients with mutiple myeloma to determine the frequency of apparent clinical manifestations of liver disease, The modification of biochemical liver tests, and histopathological abnormalities [10] .Hepatomegaly was present in $58 \%$ of cases and splenomegaly in $25 \%$. Nine patients had jaundice, with bilirubin values ranging from $3.2 \mathrm{mg} / \mathrm{dL}$ to $17.3 \mathrm{mg} / \mathrm{dL}$. Nine patients had exudative ascites.

Patients with multiple myeloma generally have elevated liver enzymes, especially alkaline phosphatase related to heavy plasmacytic infiltration of hepatic tissue [11]. Nevertheless, elevations of liver enzymes do not correlate with the presence of histologic lesions [12].In our case, there was an increase in GGT and PAL activity in association with a low prothrombin time. The authors concluded that abnormalities in liver function tests and significant plasma infiltration of the liver were common in patients with MM, but were clinically obvious in a few cases $[9,10]$.

Thomas et al. Affirm that massive hepatic infiltration consists of 2 types: tumor formation (plasmocytomas) and diffuse sinusoidal [10]. In the diffuse pattern, tumors or aggregates in the portal areas are formed by plasma cells of different degrees of differentiation that invade the sinusoidal area [13]. This diffuse hepatic infiltration needs a liver biopsy to confirm the diagnosis [14], The type forming a nodular tumor (plasmocytoma) is less frequent. This could lead to biliary obstruction by a myeloma in the liver or in the head of the pancreas $[15,16]$.

The therapeutic management of MM patients with significant hepatic dysfunction is complicated because of the difficulty of prescribing most chemotherapeutic agents that may be hepatotoxic.Dose adjustments are necessary to administer anthracyclines and vincristine in hepatic insufficiency. Steroids and new agents such as thalidomide and bortezomib may be used in these settings, although thalidomide has been cited in one case as causing fulminant hepatic dysfonction. liver toxicity has also been reported with bortezomib $[17,18]$.

A number of reports have described successful treatment with combination chemotherapy or steroids alone $[19,20]$. Multi-dose chemotherapy with stem cell transplantation (TST, autologous or allogeneic) was studied to determine whether an aggressive approach had an impact on survival.

Currently, the management guidelines do not take into consideration extramedullary disease but are circled mostly around the age of the patient and disease activity. Patients under 65 years of age with active disease are started immediately on induction therapy with thalidomide, lenalidomide, or bortezomib plus hematopoietic stem-cell transplant. Patients between 65 and 75 years of age, based on comorbidities, are considered for reduced-dose intensity autologous transplantation. However, patients older than 75 years are rarely considered for stem-cell transplant and therapy dosage is usually reduced [21].

The prognosis of the patients with MM with GI involvement was poor, even with aggressive treatment. Even though the Stem Cell Therapy was very effective in inducing remissions, the patients had rapid relapses [22-23].

Patients with extramedullary disease have more aggressive disease progression with shorter progression-free survival and overall survival [24]. When liver failure is installed the prognosis is poor and patient progresses rapidly to jaundice, coagulopathy, and encephalopathy [25]. Though current novel agents have increased overall survival of patients to more than ten years, the biologic and genetic features of multiple myeloma play a crucial role in treatment.

\section{CONCLUSION}

Hepatic involvement in $\mathrm{MM}$ is often multifactorial. It is mainly due to amyloidosis or extrahepatic biliary obstruction. On the other hand, hepatic cirrhosis of myeloma is exceptional. Its diagnosis is often difficult. It is histological based on the demonstration of hepatic plasma cell infiltration. His treatment is symptomatic but joins that of the MM. it poses a therapeutic problem because of the iatrogenic hepatic risk of myeloma chemotherapy.

\section{REFERENCES}

1. Bladé J, de Larrea CF, Rosiñol L. Extramedullary involvement in multiple myeloma. Haematologica. 2012;97(11):16181619.

2. Rahhal FE, Schade RR, Nayak A, Coleman TA. Hepatic failure caused by plasma cell infiltration in multiple myeloma. World Gastroenterol. 2009;15:2038-40.

3. Bhandari MS,Mazumder A, Vesole DH. Liver involvement in multiple myeloma.Clin lymphoma Myeloma 2007; 7:538-40

4. Usmani SZ,Heuck C, Mitchell A, Szymoniftka J, Nair B, Hoering A. Extramedullary disease protends poor prognosis in multiple myeloma and is over-represented in high-risk disease even in the era of novel agents . Heamatologica. 2012; 97:1761-7

5. Mena-Duran A, Munoz Vicente E, Pareja Llorens G, Sanchis Cervera J. Liver failure caused by light 
chain deposition disease associated with multiple myeloma. Intern Med Tokyo Jpn. 2012;51:773

6. Barth C, Bosse A, Andus T. Severe actue cholestatic hepatitis by infiltration of monoclonal plasma cells in multiple myeloma. $\mathrm{Z}$ Fur Gastroenterol. 2005; 4:1129-32

7. Kapadia SB. Multiple myeloma: a clinicopatholologic study of 62 consecutively autopsied cases. Medicine. 1980; 59:380-392.

8. Kyle RA. Multiple myeloma: review of 869 cases. Mayo Clin Proc. 1975; 50:29-40.

9. Perez-Soler R, Esteban R, Allende E. Liver involvement in multiple myeloma. Am J Hematol. $1985 ; 20: 25-29$.

10. Thomas FB, Clausen KP, Greenberger NJ. Liver disease in multiple myeloma. Arch Intern Med. $1973 ; 132: 195-202$.

11. Poudel B, Mittal A, Shrestha R, Farooqui M, Yadav S, NK, Shukla PS. Liver involvement in multiple myeloma: a hospital based retrospective study. Asian Pacific Journal of Cancer Prevention. 2012; 13 (5): 2153-2155.

12. Thomas F. B., Clausen K.P., Greenberger N. J. Liver disease in multiple myeloma. Archives of Internal Medicine. 1973; 132 (2): 195-202.

13. Waltz-Mattmuller R, Horny HP, Ruck P. Incidence and pattern of liver involvement in hematological malignancies. Path Res Pract. 1998; 194:781-789.

14. Moulopoulos LA, Granfield CA, Dimopoulos MA. Extraosseous multiple myeloma: imaging features. Am J Roentgenol 1993; 161:10831087.

15. Thiruvengadam R, Penetrante RB, Goolsby HJ. Multiple myeloma presenting as space occupying lesions of the liver. Cancer. 1990; 65:2784-2786.

16. Fischer A, Suhrland MJ, Vogl SE. Myeloma of the head of the pancreas: a case report. Cancer 1993; 67:681-683.
17. Trojan A, Chasse E, Gay B, Pichert G, Taverna C. Severe hepatic toxicity due to thalidomide in relapsed multiple myeloma. Ann Oncol. 2003;14:501-502.

18. Rosiñol L, Montoto S, Cibeira MT, Bladé J. Bortezomib-induced severe hepatitis in multiple myeloma: a case report. Arch Intern Med. 2005;165:464-465.

19. Solves P, De La Rubia J, Jarque I. Liver disease as primary manifestation of multiple myeloma in a young man. Leuk Res. 1999; 23:403-405

20. Barth C, Bosse A, Andus T. Severe acute cholestatic hepatitis by infiltration. Z Gastroenterol. 2005; 43:1129-1132.

21. Palumbo A, Anderson K. Multiple myeloma. The New England Journal of Medicine. 2011;364(11):1046-1060.

22. Michopoulos S, Petraki K, Petraki C. Light chain deposition disease of the liver without renal involvement in a patient with multiple myeloma related to liver failure and rapid fatal outcome. Dig Dis Sci 2000; 47:730-734.

23. Yamamoto T, Maeda N, Kawasaki H. Hepatic failure in a case of multiple myeloma associated amyloidosis (kappa-AL). J Gastroenterol. 1995; 30:393-397.

24. Varettoni M, Corso A, Pica G, Mangiacavalli S, Pascutto C, Lazzarino M. Incidence, presenting features and outcome of extramedullary disease in multiple myeloma: a longitudinal study on 1003 consecutive patients. Annals of Oncology. 2010;21(2):325-330.

25. Mena-Durán A, Vicente EM, Llorens GP, Cervera JS. Liver failure caused by light chain deposition disease associated with multiple myeloma. Internal Medicine. 2012;51(7):773-776. 